\title{
Epiisopiloturine hydrochloride, an imidazole alkaloid isolated from Pilocarpus microphyllus leaves, protects against naproxen-induced gastrointestinal damage in rats
}

\author{
Lucas A.D. Nicolau ${ }^{\mathrm{a}}$, Nathalia S. Carvalho ${ }^{\mathrm{b}}$, Dvison M. Pacífico ${ }^{\mathrm{c}}$, Larisse T. Lucetti ${ }^{\mathrm{a}}$, \\ Karoline S. Aragão ${ }^{a}$, Leiz M.C. Véras ${ }^{\mathrm{d}}$, Marcellus H.L.P. Souza ${ }^{\mathrm{a}}$, José R.S.A. Leite ${ }^{\mathrm{d}}$, \\ Jand Venes R. Medeiros ${ }^{\mathrm{b}, \mathrm{d}, *}$ \\ a Department of Physiology and Pharmacology, Federal University of Ceará, Fortaleza, CE, Brazil \\ ${ }^{\mathrm{b}}$ Post Graduation Program in Pharmacology, Federal University of Piauí, Teresina, PI, Brazil \\ c Post Graduation Program in Morphofunctional Sciences, Department of Morphology, Faculty of Medicine, Federal University Ceará, Fortaleza, CE, Brazil \\ d Post Graduation Program in Biotechnology, Federal University of Piauí, Parnaíba, Brazil
}

\section{A R T I C L E I N F O}

\section{Article history:}

Received 3 December 2016

Received in revised form 21 December 2016

Accepted 22 December 2016

\section{Keywords:}

Epiisopiloturine

Naproxen

Gastrointestinal

Rat

\begin{abstract}
A B S T R A C T
Objective: This study aimed to investigate the protective effect of epiisopiloturine hydrochloride (EPI), an imidazole alkaloid, on NAP-induced gastrointestinal damage in rats.

Methods: Initially, rats were pretreated with $0.5 \%$ carboxymethylcellulose (vehicle) or EPI $(3,10$ and $30 \mathrm{mg} / \mathrm{kg}$, p.o. or i.p., groups 3-5, respectively) twice daily, for 2 days. After $1 \mathrm{~h}, \mathrm{NAP}(80 \mathrm{mg} / \mathrm{kg}$, p.o. $)$ was given. The control group received only vehicle (group 1 ) or vehicle + naproxen (group 2). Rats were euthanized on 2nd day, $4 \mathrm{~h}$ after NAP treatment. Stomachs lesions were measured. Samples were collected for histological evaluation and glutathione (GSH), malonyldialdehyde (MDA), myeloperoxidase (MPO), and cytokines levels. Moreover, gastric mucosal blood flow (GMBF) was evaluated.

Results: EPI pretreatment prevented NAP-induced macro and microscopic gastric damage with a maximal effect at $10 \mathrm{mg} / \mathrm{kg}$. Histological analysis revealed that EPI decreased scores of damage caused by NAP. EPI reduced MPO ( $3.4 \pm 0.3 \mathrm{U} / \mathrm{mg}$ of gastric tissue) and inhibited changes in MDA $(70.4 \pm 8.3 \mathrm{mg} / \mathrm{g}$ of gastric tissue) and GSH (246.2 $\pm 26.4 \mathrm{mg} / \mathrm{g}$ of gastric tissue). NAP increased TNF- $\alpha$ levels, and this effect was reduced by EPI pretreatment. Furthermore, EPI increased GMBF by $15 \%$ compared with the control group. Conclusion: Our data show that EPI protects against NAP-induced gastric and intestinal damage by reducing pro-inflammatory cytokines, reducing oxidative stress, and increasing GMBF.
\end{abstract}

(C) 2016 Elsevier Masson SAS. All rights reserved.

\section{Introduction}

Nonsteroidal anti-inflammatory drugs (NSAIDs) are often used clinically because of their anti-pyretic, anti-inflammatory, and analgesic properties. However, the chronic administration of these drugs is restricted as a consequence of their capacity to cause damage to the gastrointestinal tract, such as ulceration, erosion, perforation, and hemorrhage [1]. Naproxen, a non-selective NSAID, is widely prescribed for disorders such as arthritis, and is also one of the NSAIDs most likely to induce gastrointestinal injury $[2,3]$.

\footnotetext{
* Corresponding author at: LAFFEX/BIOTEC/UFPI, Av. São Sebastião, n 2819, CEP 64202-020, Parnaíba, PI, Brazil.

E-mail address: jandvenes@ufpi.edu.br (J.V.R. Medeiros).
}

The pathophysiology of naproxen-induced gastric antral ulceration is characterized by the production of oxygen free radicals, lipid peroxidation, and increased neutrophil adherence and activation [4-6].

The plants of the Pilocarpus genus, commonly known as "jaborandi," contain 14 known alkaloids [7], including pilocarpine, which is a particularly important phytotherapeutic compound that is used in human and veterinary medicine, and produces therapeutic effects such as decreased intraocular pressure, reduced dry mouth, and stimulation of smooth muscle for the treatment of gastrointestinal complications [8]. Other alkaloids such as isopilosine, epiisopilosine, and epiisopiloturine (Fig. 1) have been isolated from jaborandi [Pilocarpus microphyllus Stapf (Rutaceae)] leaves and are structurally similar to pilocarpine [9]. Epiisopiloturine is the second-most concentrated alkaloid, and has 

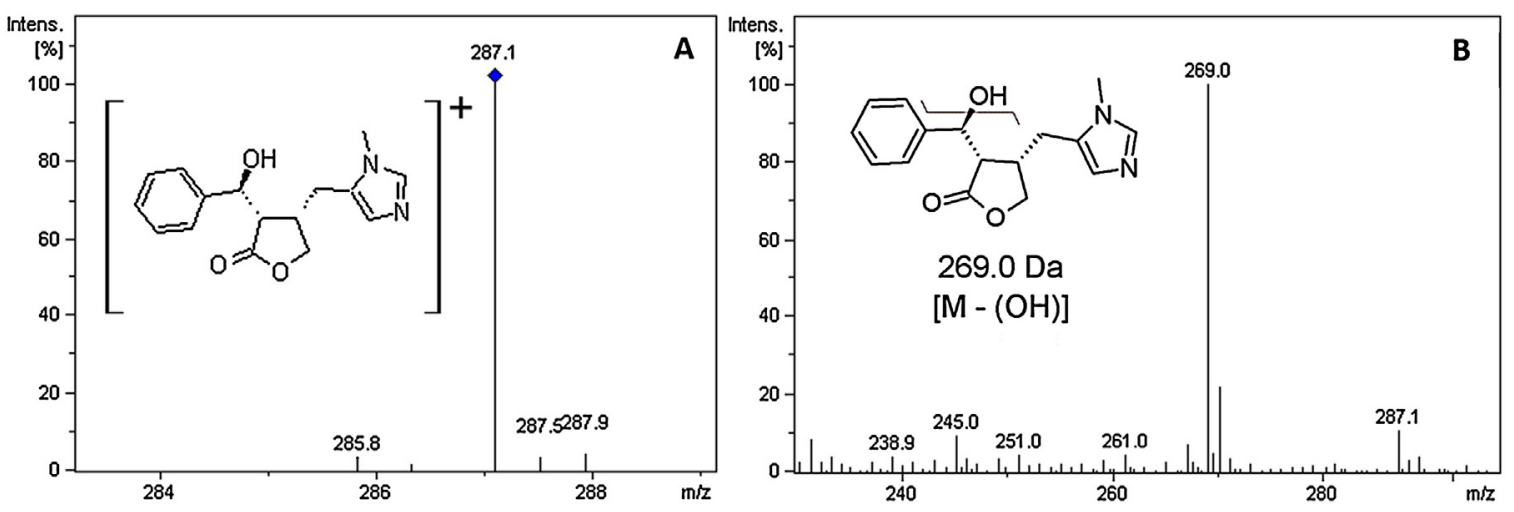

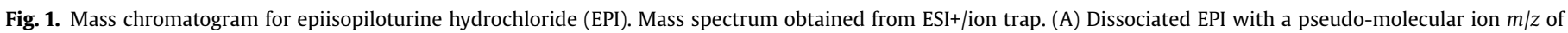
287.1 Da $[\mathrm{M}+\mathrm{H}]^{+}$, and (B) $\mathrm{MS}^{2}$ with characteristic fragment at $m / z$ of $269.0 \mathrm{Da}\left[\mathrm{M}-\mathrm{H}_{2} \mathrm{O}\right]^{+}$with proposed chemical structure.

demonstrated anti-parasitical, anti-inflammatory, and antinociceptive effects [10,11]. Natural products represent an excellent source for drug discovery; these products can be used directly to treat human diseases or can serve as a valuable starting point for drug discovery programs [12]. Although careful studies of the biological activities of Pilocarpus alkaloids and their underlying molecular mechanisms have led to the identification of novel modes of action and targets of relevance to the treatment of human diseases, no studies have examined the potential of epiisopiloturine to protect against ulcerogenic side effects associated with the use of NSAIDs. In this context, some imidazole derivatives were found to be versatile scaffolds with which to design antiinflammatory compounds, because the imidazole rings are known to possess gastric protective and ameliorative effects [13]. Furthermore, a range of alkaloids have been shown prominent place in research as scope of drugs able to improve peptic ulcers [14]. Thus, the aim of this study was to investigate the ameliorative effect of epiisopiloturine hydrochloride, a derivative imidazole alkaloid, on naproxen-induced gastrointestinal damage in rats.

\section{Materials and methods}

\subsection{Plant material}

A specimen of Pilocarpus microphyllus was collected in October 2008 near Matias Olímpio City (Piauí, Brazil) and was identified by Dr. Ivanilza Moreira de Andrade of the Department of Biology, Federal University of Piauí. A voucher specimen (TEPB 27.152) was deposited at the Graziella Barroso Herbarium (Teresina, Piauí, Brazil).

\subsection{Characterization}

Epiisopiloturine (EPI), shown in Fig. 1, was obtained from waste produced by pilocarpine extraction from $P$. microphyllus leaves according to a previous study [10]. For being an alkaloid, the natural form of EPI is presented as basis without charge. In reaction with an acid, formed a soluble salt that was obtained by slow evaporation of the solution and exhibited MS/MS data consistent with values in the literature, as determined with an AmaZon SL mass spectrometer (Bruker Daltonics, Bremen, Germany) [15].

\subsection{Drugs and reagents}

Naproxen, carboxymethylcellulose, omeprazole, histamine, and ranitidine were purchased from Sigma-Aldrich Chemical (Saint
Louis, MO, USA). Naproxen was dissolved in 0.5\% carboxymethylcellulose $(\mathrm{w} / \mathrm{v})$. EPI was dissolved in $0.9 \% \mathrm{NaCl}$.

\subsection{Animals}

Male Wistar rats, weighing 120-150 g, were housed in temperature-controlled rooms and received water and food ad libitum. The animals were deprived of food for $18-24 \mathrm{~h}$ before the experimentation, but had free access to water. All surgical procedures and animal treatments were conducted in accordance with the Guide for the Care and Use of Laboratory Animals (National Institutes of Health, Bethesda, MD) and were approved by the local ethics committee (Protocol number 008/2012).

\subsection{Effect of EPI on naproxen-induced gastrointestinal damage}

Rats were pretreated with $0.5 \%$ carboxymethylcellulose (vehicle), epiisopiloturine EPI (3,10, and $30 \mathrm{mg} / \mathrm{kg}$, p.o.; 3, 10, and $30 \mathrm{mg} /$ $\mathrm{kg}$, i.p., groups 3-8 respectively) or omeprazole $(10 \mathrm{mg} / \mathrm{kg}$, p.o., group 9) twice per day (at 09:00 and 21:00) for 2 days. One hour after EPI administration, naproxen $(80 \mathrm{mg} / \mathrm{kg}$, p.o.) was administered (at 10:00 and 22:00) for 2 days as described by Kim et al. [3] with modifications. The control group received only vehicle (group 1 ) or vehicle + naproxen (group 2). The rats were killed on the second day, $4 \mathrm{~h}$ after the naproxen treatment. The stomachs were promptly excised, opened along the greater curvature. The gastric damage was measured using digital calipers (Mitutoyo ${ }^{\circledR}$, IL, USA). To study intestinal damage the abdomens were opened, and after identification of the intestine, a $5-\mathrm{cm}$ portion of the medial intestine was removed for the evaluation of macroscopic scores by the criteria described by Martin and Wallace [16] with some modifications. All scoring of damage was performed in a randomized manner by an observer who was unaware of the treatments that the rats had received. Samples of the stomachs and small intestine were used for posterior analysis.

\subsection{Glutathione (GSH) level}

A segment from stomach and small intestine was homogenized in $5 \mathrm{~mL}$ of cold $0.02 \mathrm{M}$ EDTA solution ( $1 \mathrm{~mL}$ per $100 \mathrm{mg} /$ tissue). Aliquots $(400 \mathrm{~mL})$ of the tissue homogenate were mixed with $320 \mathrm{~mL}$ of distilled water and $80 \mathrm{~mL}$ of $50 \%(\mathrm{w} / \mathrm{v})$ trichloroacetic acid in glass tubes and centrifuged at $3000 \mathrm{rpm}$ for $15 \mathrm{~min}$ (Eppendorf $^{\mathbb{B}}$ centrifuge 5810r, Germany). Next, $400 \mathrm{~mL}$ of each supernatant was mixed with $800 \mu \mathrm{L}$ of Tris buffer $(0.4 \mathrm{M}, \mathrm{pH} 8.9)$

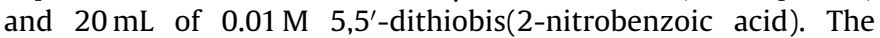


samples were stirred for $3 \mathrm{~min}$ and assayed on a spectrophotometer (Instrutherm ${ }^{\circledR}$, SP, Brazil) at $412 \mathrm{~nm}$ [17]. The results are expressed as micrograms of GSH per gram of tissue.

\subsection{Malondialdehyde (MDA) concentration}

Fragments of the gastric mucosa and small intestine weighing between 100 and $150 \mathrm{mg}$ were homogenized with cold $1.15 \% \mathrm{KCl}$ to prepare $10 \%$ homogenates. Briefly, $250 \mu \mathrm{L}$ of each homogenate was added to $1.5 \mathrm{~mL}$ of $1 \%$ phosphoric acid $\left(\mathrm{H}_{3} \mathrm{PO}_{4}\right)$ and $0.5 \mathrm{~mL}$ of $0.6 \%$ tert-butyl alcohol (aqueous solution). Then, this mixture was stirred and heated in a boiling water bath for $45 \mathrm{~min}$. The mixture was then cooled immediately in an ice water bath followed by the addition of $4 \mathrm{~mL}$ of $n$-butanol. This mixture was shaken and the butanol layer was separated by centrifugation at $1200 \times \mathrm{g}$ for $10 \mathrm{~min}$. Optical density was determined at 535 and $520 \mathrm{~nm}$, and the optical density difference between the 2 determinations was calculated as the tert-butyl alcohol value [18]. MDA concentrations are expressed as millimoles per gram of tissue.

\subsection{Myeloperoxidase (MPO) activity}

Briefly, $50-100 \mathrm{mg}$ of tissue was homogenized in $1 \mathrm{~mL}$ of potassium buffer with $0.5 \%$ of hexadecyltrimethylammonium bromide (HTAB) per $50 \mathrm{mg}$ of tissue. The homogenate was centrifuged at $40,000 \times \mathrm{g}$ for $7 \mathrm{~min}$ at $4{ }^{\circ} \mathrm{C}$. MPO activity in the resuspended pellet was assayed by measuring the change in absorbance at $450 \mathrm{~nm}$ using o-dianisidine dihydrochloride and $1 \%$ hydrogen peroxide [19]. The results were reported as the MPO units per mg of tissue. A unit of MPO activity was defined as that converting $1 \mathrm{mmol}$ of hydrogen peroxide to water in $1 \mathrm{~min}$ at $22^{\circ} \mathrm{C}$.

\subsection{Histological evaluation of gastric damage}

For histological evaluation, the stomach and small intestine samples were fixed in $10 \%$ formalin solution for $24 \mathrm{~h}$. After fixation, the samples were transferred to a solution of $70 \%$ alcohol. The material was then embedded in paraffin and sectioned with a microtome; $4-\mu \mathrm{m}$ thick sections were deparaffinized, attached on a slide, stained with hematoxylin and eosin ( $\mathrm{H} \& \mathrm{E})$, and examined under a light microscope equipped with a high-resolution Leica DFC 320 digital camera (Wetzlar, Germany) connected to a computer with an image capture program by an experienced pathologist without knowledge of the treatments. The specimens were assessed according to the criteria described by Laine and Weinstein [20], in which case scores are attributed to the following parameters for a maximum total score of 14: hemorrhagic damage (score of 0-4), edema in the upper mucosa (score of 0-4), epithelial cell loss (score of 0-3), and presence of inflammatory cells (score of $0-3)$.

\subsection{Intestinal morphometric analysis}

Morphometric analysis was performed using slides stained with H\&E on a light microscope equipped with a high-resolution Leica DFC 320 digital camera (Wetzlar, Germany) connected to a computer with an image capture program. An average of 8 to 10 different linear measurements of crypt depth and villus height were recorded. The height of the villus was measured from the top to the bottom, corresponding to the junction of the crypt and villus. The depth of the crypts was defined as the invagination between adjacent villi.

\subsection{Gastric acid secretion}

First, pylorus ligation was performed under inhalation anesthesia, and CMC and EPI ( $10 \mathrm{mg} / \mathrm{kg}$ ) were injected intraperitoneally. In another group, gastric acid secretion in pylorus-ligated mice induced by histamine $(5 \mathrm{mg} / \mathrm{kg})$ or ranitidine $(5 \mathrm{mg} / \mathrm{kg})$ via i.p. injection was tested. After $4 \mathrm{~h}$, the animals were sacrificed by deep inhalation anesthesia, the stomachs were opened, and the gastric contents were collected. The final volume and $\mathrm{pH}$ were directly
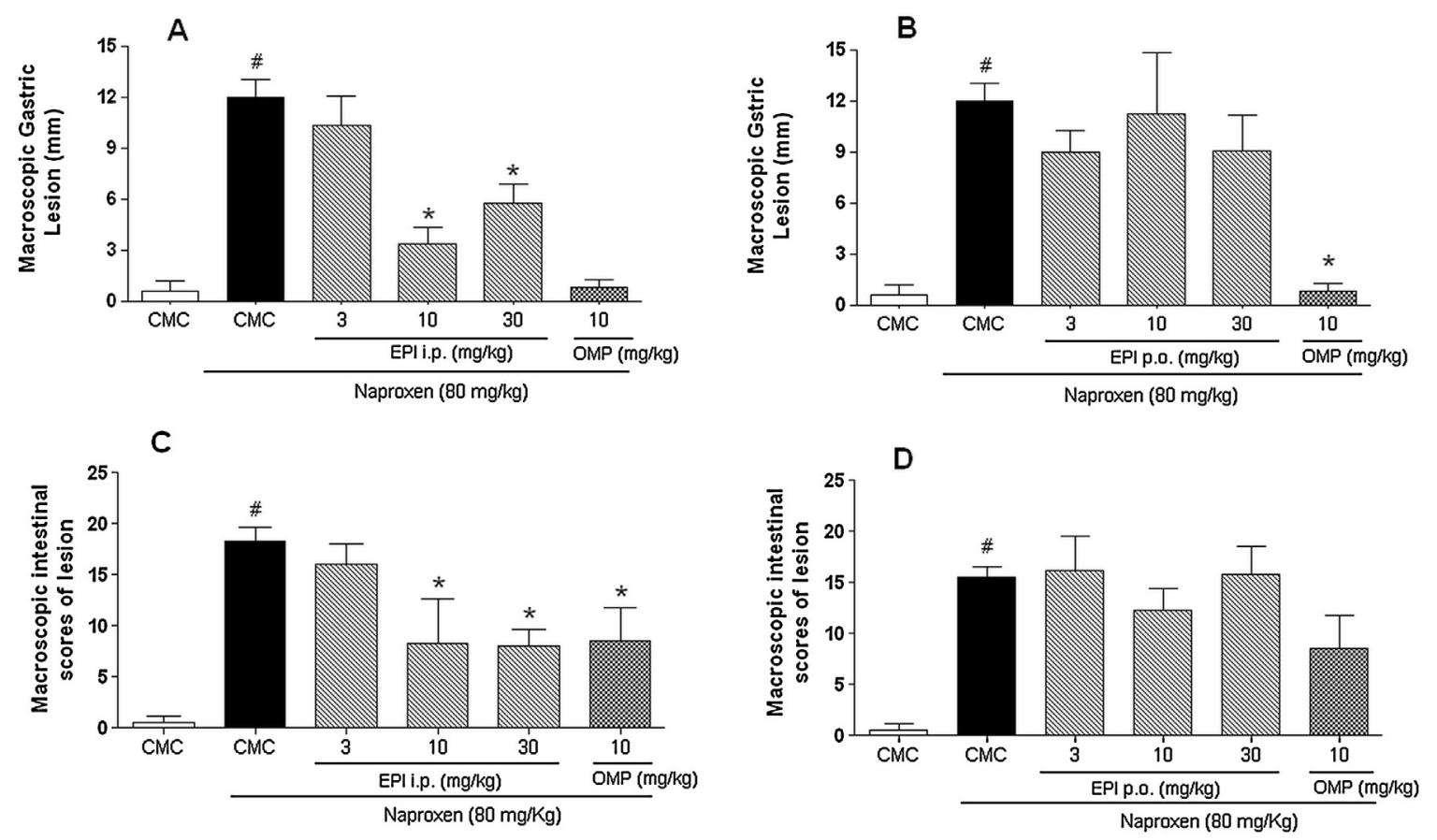

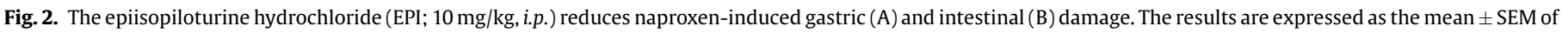
5-7 animals per group. ${ }^{*} P<0.05$ vs. carboxymethylcellulose group; $\# P<0.05$ vs. naproxen group (ANOVA and Newman-Keuls test). 
determined after washing the mucosal side of the stomach with $2 \mathrm{~mL}$ of distilled water. Total acidity of the gastric juice was titrated with $0.01 \mathrm{~N} \mathrm{NaOH}$, using $2 \%$ phenolphthalein as an indicator [21].

\subsection{Measurement of the amount of mucus adhered to the gastric wall}

Glandular segments from the stomachs were collected and weighed. Each segment was transferred to $1 \%$ Alcian blue solution. The mucus dye complex was extracted by placing the segments in $0.5 \mathrm{M} \mathrm{MgCl} 2$ for $2 \mathrm{~h}$. The dye extract was mixed with diethyl ether, centrifuged at $1400 \times \mathrm{g}$ for $10 \mathrm{~min}$, and absorbance of the supernatants was measured at $598 \mathrm{~nm}$. The quantity of extracted Alcian blue ( $\mathrm{mg} / \mathrm{g}$ of glandular tissue) was then calculated using a standard curve of Alcian blue.

\subsection{Cytokine measurements}

Samples of gastric tissue were collected and homogenized in sterile saline. After that, the levels of interleukins TNF- $\alpha$, IL-1 $\beta$, and IL-10 were evaluated using sandwich ELISA kits according to the manufacturer's recommendations (ELISA microplate reader SpectraMAX 190, Molecular Devices, CA, USA). The homogenates were centrifuged at $0.8 \mathrm{~g}$ at $4{ }^{\circ} \mathrm{C}$ for $10 \mathrm{~min}$, and supernatants were stored at $-80^{\circ} \mathrm{C}$ until further analysis. The results are expressed as pictograms per milliliter of homogenate $(\mathrm{pg} / \mathrm{mg})$ and reported as mean \pm SD.

\subsection{Evaluation of gastric blood flow}

The effect of EPI on gastric mucosal blood flow (GMBF) was evaluated ex vivo by Laser Doppler flowmetry (transonic). The responses were analyzed as GMBF variation compared to basal blood flow obtained in the initial $5 \mathrm{~min}$ of measurement. Results were expressed in units of tissue perfusion (UTP) [22].

\subsection{Statistical analysis}

Data were described as either means \pm SEM or medians, as appropriate. Analysis of variance (ANOVA) followed by the Student-Newman-Keuls test was used to compare means, and the Kruskal-Wallis nonparametric test followed by Dunn's test was used to compare medians. A $P$-value $<0.05$ was defined as statistically significant.

\section{Results}

\subsection{Effect of EPI on naproxen-induced gastrointestinal damage}

In the current study, we confirmed that treatment of the animals with naproxen for two days produced the formation of severe macroscopic gastric and intestinal lesions $(10.65 \pm 0.620 \mathrm{~mm}$ and
$18.33 \pm 1.308$ lesion scores, respectively). Fig. 2 shows that EPI prevented naproxen-induced macroscopic gastric damage in a tendency dose-dependent manner reaching its maximal effect at doses of 10 and $30 \mathrm{mg} / \mathrm{kg}$ i.p., with $68.07 \%$ and $62.81 \%$ lesion inhibition in the stomach respectively. Besides, in the small intestine macroscopic evaluation, EPI had presented protection at 10 and $30 \mathrm{mg} / \mathrm{kg}$ i.p. doses with (52.75\% and 57.38\% lesion inhibition respectively). Because the EPI dose of $10 \mathrm{mg} / \mathrm{kg}$ i.p. afforded the most protection against gastric lesions induced by naproxen, this dose was selected for the study of the possible mechanisms of action involved in EPI mediated ameliorative effects.

\subsection{Histopathological analysis}

The gastroprotective effect of $10 \mathrm{mg} / \mathrm{kg}$ EPI was confirmed by histological analysis (Table 1). Microscopic analysis revealed that naproxen increased hemorrhagic damage, edema, epithelial cell loss and inflammatory cell infiltration. In contrast, pretreatment with EPI significantly decreased the infiltration of inflammatory cells, the formation of edema and the loss of epithelial cells induced by naproxen (Fig. 3). Thus, the analysis of both the macro and microscopic results revealed an excellent association between these parameters, confirming the efficacy of the EPI molecule.

\subsection{Morphometric analyses of the medial intestine}

Significant villi shortening (Fig. 4A) and increased crypt depth (Fig. 4B) were observed in the medial intestine of rats treated with naproxen $(80 \mathrm{mg} / \mathrm{kg}$, p.o. $)$ twice daily for two days. However, when rats were pretreated with EPI i.p., we observed a complete reversal of these morphometric alterations in the medial intestine (Fig. 4A and $\mathrm{B}$ ).

\subsection{MPO activity}

In this study, we observed significantly increased levels of MPO in the stomach and the medial intestine of naproxen-treated rats compared to the control group (Table 2). However, pretreatment with $10 \mathrm{mg} / \mathrm{kg}$ EPI i.p. significantly attenuated the naproxeninduced increase in MPO activity, in the stomach and also attenuated in the intestine. Therefore, EPI may protect the gastrointestinal tissue by reducing the recruitment of leukocytes, thereby hindering superoxide anion production.

\subsection{Analysis of the GSH concentration and determination of MDA levels}

Naproxen significantly reduced the levels of GSH of both the stomach and intestine. Furthermore, increased the concentration of gastric mucosal MDA and in the intestine samples of rats (Table 2). Compared to the naproxen group, the group pretreated

Table 1

Effect of epiisopiloturine hydrochloride (EPI $10 \mathrm{mg} / \mathrm{kg}$ ) isolated from Pilocarpus microphyllus leaves on naproxen-induced microscopic gastric damage.

\begin{tabular}{|c|c|c|c|c|c|}
\hline Experimental Group $(n=5)$ & Hemorragic Damage (score, 0-4) & $\begin{array}{l}\text { Edema } \\
\text { (score, 0-4) }\end{array}$ & $\begin{array}{l}\text { Epithelial cell loss } \\
\text { (score, } 0-3 \text { ) }\end{array}$ & $\begin{array}{l}\text { Inflammatory cells } \\
\text { (score, } 0-3)\end{array}$ & $\begin{array}{l}\text { Total } \\
\text { (score, 0-14) }\end{array}$ \\
\hline Control & $0(0-1)$ & 0 & 0 & 0 & 0 \\
\hline Naproxen & $2(2-3)$ & $2(2-3)$ & $3(2-3)$ & $2(2-3)$ & $9(9-11)$ \\
\hline EPI i.p. & $1(0-2)$ & $1(0-1)^{*}$ & $0(0-1)^{*}$ & $0(0-1)^{*}$ & $3(0-5)^{*}$ \\
\hline EPI p.o. & $3(2-3)$ & $2(1-2)$ & $2(1-3)$ & $2(1-3)$ & $8(5-11)$ \\
\hline Omeprazole & $0(0-1)^{*}$ & $0(0-1)^{*}$ & $0(0-1)^{*}$ & $0(0-1)^{*}$ & $1(0-4)^{*}$ \\
\hline
\end{tabular}

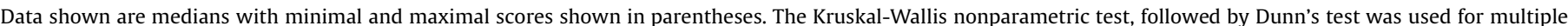
comparisons of histological analyses. 


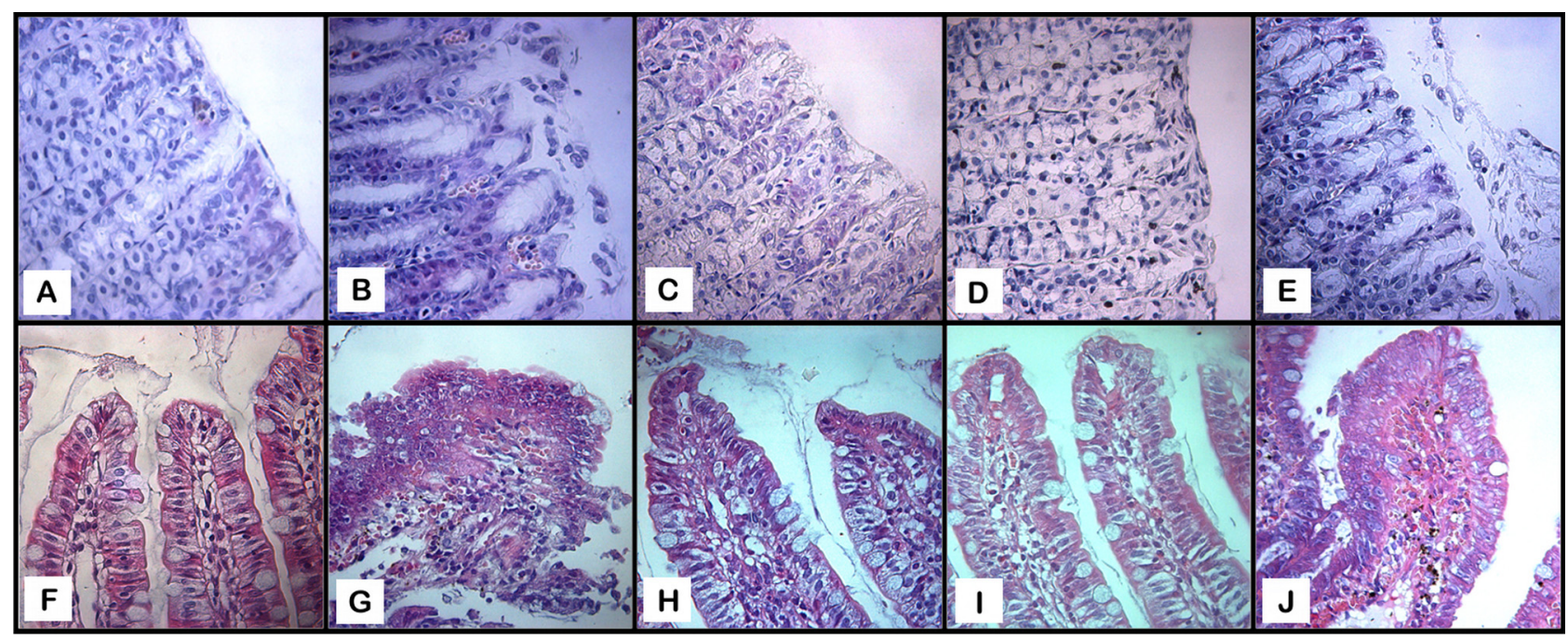

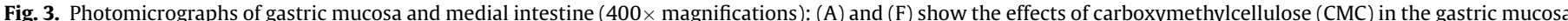

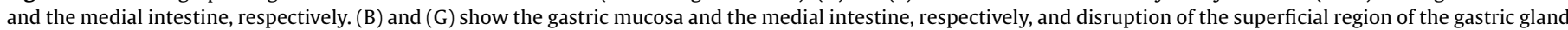

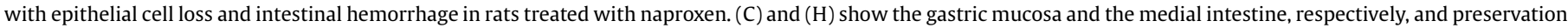

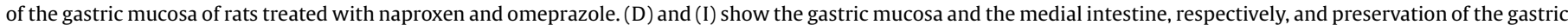

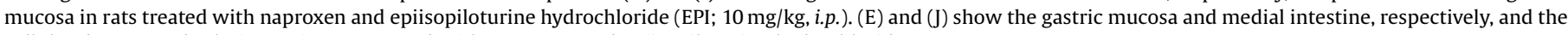
cellular damage to both tissues in rats treated with naproxen and epiisopiloturine hydrochloride.

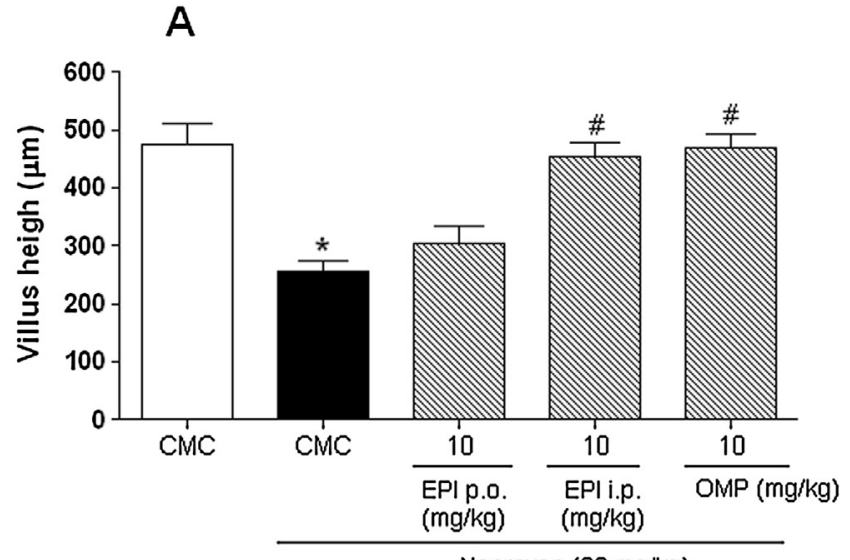

Naproxen $(80 \mathrm{mg} / \mathrm{kg})$

B

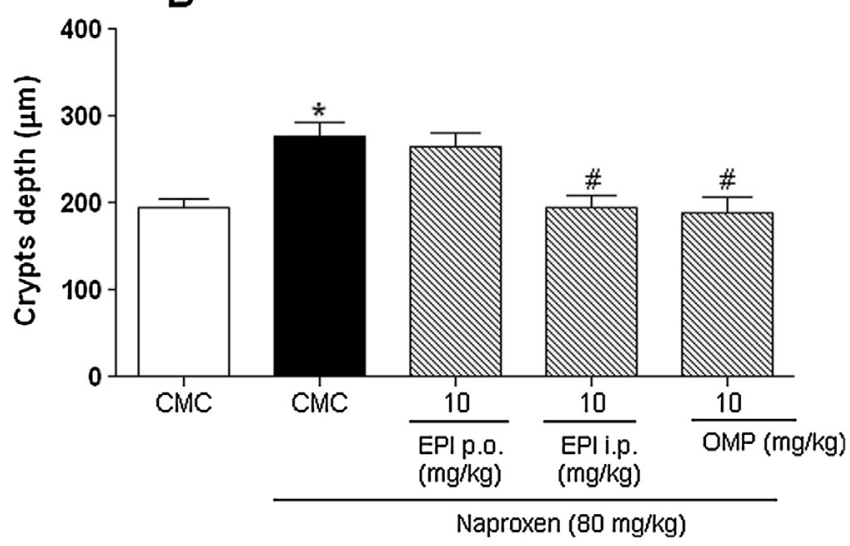

Fig. 4. Morphometric analyses of medial intestine tissues in rats treated with naproxen alone or naproxen and epiisopiloturine hydrochloride (EPI). After treatments, segments of the medial intestine were collected for the measurement of villus height (A) and crypt depth (B). Results were expressed as the mean \pm SEM of 5-7 animals per group. ${ }^{*} P<0.05$ vs. carboxymethylcellulose group; $\# P<0.05$ vs. naproxen group (ANOVA and Newman-Keuls test). with EPI $10 \mathrm{mg} / \mathrm{kg}$ i.p. showed significant enhance of GSH level on gastric tissue and on medial intestine tissue (Table 2).

In addition, pretreatment with EPI on a dose of $10 \mathrm{mg} / \mathrm{kg}$ p.o. did not play significant alteration in MDA concentration on stomach and intestine samples compared with naproxen group, however EPI on a dose of $10 \mathrm{mg} / \mathrm{kg}$ i.p. inhibited these effects in all of the naproxen-treated rats, reducing the naproxen effects and resulting in values that approximated those of controls only with vehicle $0.5 \%$ carboxymethylcellulose (Table 2 ). These results suggested that the gastroprotective effect of EPI involves the participation of oxidative stress and its blockade.

\subsection{Levels of mucus}

In Table 3, we observed that naproxen decreased significantly the amount of gastric adherent mucus when compared to the control group (CMC). Likewise, EPI ( $10 \mathrm{mg} / \mathrm{kg}$ i.p. or p.o.) pretreatment did not modify significantly this effect of naproxen. Therefore, mucus amount adhered on gastric wall shows no significant change when animals receive EPI in each of both routes (i.p. or p.o.).

\subsection{Gastric acid secretion in 4-h pylorus-ligated rats}

In this study, compared to the values obtained in the CMC group, values of the animals pretreated with EPI $(10 \mathrm{mg} / \mathrm{kg}$ i.p. or $p$. o.) showed no change in any biochemical parameter of the gastric juice such as the volume, $\mathrm{pH}$ or total acidity. In contrast, the volume and total acidity values in the group treated with ranitidine (a histamine [H2] antagonist) were decreased and increased by histamine compared to the corresponding values in the saline group as shown in Table 3.

\subsection{Cytokine measurements}

Due to the great results in the gastric site, cytokines measurements were performed only in its tissue. Administration of naproxen resulted in increasing gastric levels of cytokines (TNF$\alpha$, IL-1 $\beta$ and IL-10) when compared with the control group. EPI 
Table 2

Effects of Epiisopiloturine Hydrochloride $(10 \mathrm{mg} / \mathrm{kg}$ ) at biochemical dosages of MPO, GSH, MDA and cytokines (TNF- $\alpha$, IL-1 $\beta$ and IL-10).

\begin{tabular}{|c|c|c|c|c|c|c|}
\hline Experimental Group $(n=5)$ & MPO U/mg tissue & GSH mg/g tissue & MDA nmol/g tissue & TNF- $\alpha \mathrm{pg} / \mathrm{ml}$ tissue & IL- $1 \beta \mathrm{pg} / \mathrm{ml}$ tissue & IL-10 pg/ml tissue \\
\hline Control (stomach) & $3.56 \pm 1.33$ & $324.6 \pm 38.9$ & $82.23 \pm 9.42$ & $535.6 \pm 132.7$ & $458.0 \pm 124.8$ & $676.0 \pm 182.5$ \\
\hline Naproxen (stomach) & $10.97 \pm 1.87$ & $67.3 \pm 8.34$ & $157.3 \pm 18.1$ & $988.2 \pm 52.01$ & $1523 \pm 325.4$ & $1333 \pm 97.52$ \\
\hline EPI i.p. (stomach) & $3.44 \pm 0.31^{*}$ & $258.7 \pm 30.13^{*}$ & $70.43 \pm 8.32^{*}$ & $700.5 \pm 59.95$ & $1567 \pm 247.6$ & $956.3 \pm 102.0$ \\
\hline EPI p.o. (stomach) & $8.83 \pm 2.36$ & $142.9 \pm 24.92$ & $130.3 \pm 17.6$ & $1078 \pm 114.7$ & $2443 \pm 280.1$ & $1281 \pm 221.0$ \\
\hline Omeprazole (stomach) & $3.48 \pm 1.26^{*}$ & $206.6 \pm 10.23^{*}$ & $82.23 \pm 9.41^{*}$ & - & - & - \\
\hline Control (intestine) & $7.70 \pm 0.95$ & $353.0 \pm 19.19$ & $135.1 \pm 12.16$ & - & - & - \\
\hline Naproxen (intestine) & $18.39 \pm 1.56$ & $80.63 \pm 17.51$ & $313.9 \pm 33.34$ & - & - & - \\
\hline EPI i.p. (intestine) & $11.39 \pm 2.69^{\#}$ & $189.5 \pm 27.27^{\#}$ & $301.0 \pm 43.81$ & - & - & - \\
\hline EPI p.o. (intestine) & $14.84 \pm 1.41$ & $107.3 \pm 22.82$ & $315.3 \pm 59.40$ & - & - & - \\
\hline Omeprazole (intestine) & $4.56 \pm 1.46^{\#}$ & $309.8 \pm 21.48^{\#}$ & $135.1 \pm 12.16^{\#}$ & - & - & - \\
\hline
\end{tabular}

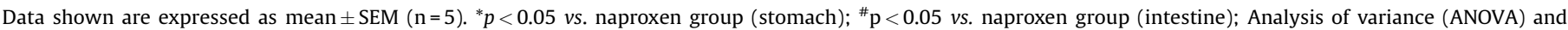
Newman-Keuls test.

Table 3

Effects of epiisopiloturine hydrochloride $(10 \mathrm{mg} / \mathrm{kg})$ at amount of mucus adhered to the gastric wall and gastric acid secretion.

\begin{tabular}{|c|c|c|c|c|}
\hline Experimental Group $(\mathrm{N}=5)$ & Levels of mucus ( $\mu \mathrm{g} / \mathrm{g}$ tissue) & Volume $(\mu \mathrm{l})$ & $\mathrm{pH}$ & Total Acid $(\mathrm{mEq}[\mathrm{H}+] / \mathrm{l} / 4 \mathrm{~h})$ \\
\hline Naproxen & $0.022 \pm 0.0057^{\#}$ & - & - & - \\
\hline Omeprazole & $0.086 \pm 0.0134^{\#}$ & - & - & - \\
\hline Control & $0.081 \pm 0.0074$ & $492 \pm 20.4$ & $1.7 \pm 0.5$ & $5.6 \pm 0.8$ \\
\hline EPI i.p & $0.026 \pm 0.0061$ & $512 \pm 65.9$ & $1.5 \pm 0.5$ & $6.0 \pm 0.4$ \\
\hline EPI v.o & $0.026 \pm 0.0041$ & $499 \pm 32.1$ & $1.4 \pm 0.4$ & $6.2 \pm 0.6$ \\
\hline Histamine & - & $1149 \pm 100.2^{\#}$ & $1.2 \pm 0.2$ & $11 \pm 0.5^{\#}$ \\
\hline Ranitidine & - & $233 \pm 59.5^{\#}$ & $3.1 \pm 0.7$ & $2.0 \pm 0.3^{\#}$ \\
\hline
\end{tabular}

Data shown are expressed as mean \pm SEM $(n=5)$. \#p $<0.05$ vs. control group; Analysis of variance (ANOVA) and Newman-Keuls test.

( $10 \mathrm{mg} / \mathrm{kg}$ i.p.) pretreatment reduced the levels of TNF- $\alpha$ and IL-10, but kept similar IL-1 $\beta$ levels (Table 2 ).

\subsection{Gastric mucosal blood flow (GMBF)}

As shown in Fig. 5, GMBF was significantly higher of 15\% in EPI $(10 \mathrm{mg} / \mathrm{kg}$, i.p.) than that in the control group rates (data in percentage by Units of Tissue Perfusion). No effects on blood flow

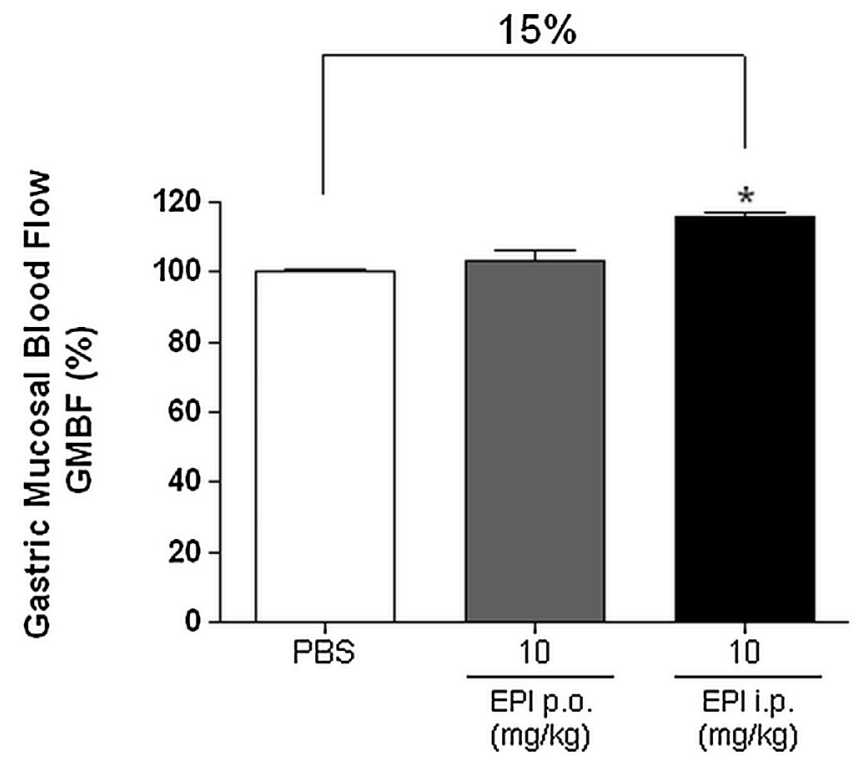

Fig. 5. Effect of epiisopiloturine hydrochloride (EPI; $10 \mathrm{mg} / \mathrm{kg}$, i.p. or applied directly onto the gastric tissue) on gastric mucosal blood flow (GMBF). The results are expressed as the mean \pm SEM of 5 animals per group. GMBF is expressed as\% increase from basal values. ${ }^{*} \mathrm{P}<0.05$ vs. control values (ANOVA and Newman-Keuls test). were observed with EPI $10 \mathrm{mg} / \mathrm{kg}$, directly on mucosal tissue which mimics an oral administration by gavage.

\section{Discussion}

The analysis of MS data, confirm the formation of a new compound, protonated in the nitrogen from imidazole ring and chloride ions. Although our new data shows the alkaloid epiisopiloturine in salt form, the crystal form when in aqueous media intends to be the purposed biomolecule epiisopiloturine. Based on our previous experience with difficult solubility of epiisopiloturine on base form, we choose to focus initially to modify structure of epiisopiloturine molecule aiming to improve its solubilization in aqueous media. Furthermore, other advantage resulting from the modification was to gain increased stability presented by the alkaloid salt.

Recently, a review has listed fifteen alkaloids applied to different experimental models of peptic ulcers, including ulcers caused by NSAIDs. Several mechanisms are involved in the defense of the gastrointestinal tissue by alkaloids, and it revealed common peculiarities as immunomodulation, increased gastric blood flow and participation of the endogenous antioxidant system [14]. Most alkaloids are crystalline substances, which dissolve poorly in water due to their low solubility grade into aqueous systems of preparation [23]. Our research group studied the antiinflammatory and antinociceptive activity of epiisopiloturine in its crude formulation; however it was possible carry on the alkaloid solubilized only in $2 \%$ DMSO [11].

The results of this research imply a protective role of epiisopiloturine hydrochloride (EPI), a semisynthetic derivative of epiisopiloturine, against gastrointestinal damage. We demonstrate in inedited character that EPI prevented naproxen-induced macroscopic gastric and intestinal damage. The ameliorative effect of EPI in gastric tissue was confirmed by histological analysis. EPI intraperitoneally significantly decreased the infiltration of inflammatory cells, the formation of edema, and the loss of epithelial cells 
induced by naproxen. Thus, analysis of both the macroscopic and microscopic results of this study confirmed the efficacy of EPI.

Significant villi shortening and increased crypt depth were observed in the medial intestine of rats treated with naproxen. However, when rats were pretreated with EPI (i.p.), we observed a complete reversal of these morphometric alterations in the medial intestine. Other studies have shown that the development of NSAIDinduced small intestinal ulcers is a multifactorial process with a distinct pathogenesis via gastric damage that involves a combination of events [24,25], such as increased epithelial permeability [26], intestinal hypermotility [27], and luminal bacterial invasion of the gut wall [28]. These effects lead to mucosal inflammation and eventually result in macroscopic damage. Taken together, these results indicate that EPI has a significant ameliorative effect against naproxen-induced gastrointestinal damage.

Myeloperoxidase (MPO) is a marker enzyme for inflammation and neutrophil infiltration that is known to be increased under GI tract ulcerated conditions and reduced during the healing process [29]. In this study, we observed significantly increased levels of MPO activity in the stomach and the medial intestine of naproxentreated rats. However, pretreatment with EPI (i.p.) significantly attenuated the naproxen-induced increase in MPO activity in the stomach and the intestine. Therefore, EPI may protect the gastrointestinal tissue by reducing the recruitment of leukocytes, thereby hindering superoxide anion production. Thus, the suppression of neutrophil infiltration into the gastrointestinal mucosa may contribute to the ameliorative effect of EPI against naproxen lesions. Other studies show that alkaloids can prevent oxidative stress and produce anti-inflammatory effects by inhibiting neutrophil infiltration associated with gastrointestinal damage induced by NSAIDs in rats [14].

Gastrointestinal damage induced by naproxen is associated with oxidative stress mediated by the generation of free radicals and lipid peroxidation, as well increased production of proinflammatory cytokines (such as IL-1 $\beta$ and TNF- $\alpha$ ) in gastric mucosa tissue and the plasma [14]. Overproduction or unsuitable production of proinflammatory cytokines can result in conditions which involve tissue damage and exacerbation of inflammation $[30,31]$. Our results show that administration of naproxen increase the levels of cytokines (TNF- $\alpha$ and IL-1 $\beta$ ) in gastric tissue, as compared with the control group. EPI pretreatment reduced the levels of TNF- $\alpha$, but did not change IL- $1 \beta$ levels. Gastric IL-10 levels were also significantly elevated in groups treated with EPI and naproxen, indicating that this cytokine was triggered in a similar manner to the proinflammatory cytokine TNF- $\alpha$ in rats treated with naproxen. Gastric IL-10 levels were increased in naproxentreated animals, but diminished in animals treated with EPI and naproxen, possibly reflecting attenuation of inflammation at the ulcer margin. This profile was observed in other studies on the involvement of IL-10 in gastric damage, ie, it is expected that IL-10 antagonizes the effect of pro inflammatory cytokines, however in cases of a sub-chronic experimental models, it may be a compensatory response due to the reestablishment of tissue architecture as well as the return of their healthy rearrangement [32,33].

The local generation of oxygen-derived free radicals such as superoxide $\left({ }^{\bullet} \mathrm{O}_{2}^{-}\right)$and hydroxyl radicals $\left({ }^{\bullet} \mathrm{OH}^{-}\right)$, as well as other cytotoxic oxygen metabolites, may result in damage such as gastrointestinal mucosal bleeding and ischemia-reperfusion [34]. However, complex antioxidant systems such as radical scavengers and inhibitors of free radical production prevented oxidative damage caused by high free radical concentrations [35]. In the present study, two important oxidative stress markers were analyzed: glutathione (GSH) and malondialdehyde (MDA). Compared to the naproxen group, the group pretreated with EPI (i.p.) showed significantly enhanced in GSH and MDA levels in gastric and intestinal tissue. These results showed that the gastroprotective effect of EPI involves the blockade of oxidative stress.

Homeostatic equilibrium is maintained by the balance of gastric acid and mucus secretion, which maintains the integrity of the gastrointestinal mucosa. If this homeostasis is impaired, mucosal erosions and ulceration can occur [36]. Some studies have shown that the development of NSAID-induced gastric mucosal injury involves increased gastric acid secretion and reduced mucus synthesis [37,38]. We observed that naproxen significantly decreased the amount of gastric adherent mucus when compared to the CMC-treated control group, and that EPI pretreatment did not significantly influence the naproxen harmful effect. Likewise, pretreatment with EPI has kept significantly unaltered the gastric juice analyzed parameters of volume, $\mathrm{pH}$ and total acids.

Gastric ulceration due to the ingestion of NSAIDs appears to be associated with a reduction in gastric mucosal blood flow (GMBF) and an increase in leukocyte adherence within the gastric microcirculation, secondary to a reduction in prostaglandin synthesis [39]. As shown, GMBF was significantly increased by $15 \%$ in the epi-treated group as compared to the control group. These results show a crucial participation of gastric blood flow in the gastroprotective effect of intraperitoneally administered EPI, which corroborates the data described in this study.

Our results indicate that intraperitoneal, but not oral, EPI protects against naproxen-induced gastrointestinal damage. The peritoneum is a cavity which has been successfully utilized by several areas in pharmacology research. The physiologic characteristic of the peritoneal cavity not only helps remove toxic metabolites from the body, but also provides a useful portal of entry in the body for several pharmacological agents. The intraperitoneal route is used for treatment of renal failure and more recently the intraperitoneal route has been used for chemotherapy in patients with intra-abdominal malignancies [40]. Thus, intraperitoneal route is an alternate route to the more conventional drug delivery routes, and can be successfully used when the target is within the peritoneal cavity or adjacent tissue.

In conclusion, our work explored a novel therapeutic strategy for NAP-induced gastrointestinal damage and the ameliorative effects of EPI administration may be related to decreases in free radical production and lipid peroxidation. Moreover, EPI also down-regulates pro-inflammatory cytokine TNF- $\alpha$. In addition, the increased gastric mucosal blood flow induced by EPI reveals an important defense mechanism, since this alteration leads to free radicals scavenging and promotes gastric cell nutrition. Thus, we purpose that EPI represents an attractive new treatment strategy for the prevention of NSAID-induced gastrointestinal lesions.

\section{Conflict of interest}

Authors declare no conflict of interests concerning this work.

\section{Acknowledgments}

The authors gratefully acknowledge the financial support from National Counsel of Technological and Scientific Development CNPq (Brazil) and Research foundation for the State of Piauí FAPEPI. Dr. Leite, Dr. Souza and Dr. Medeiros are recipients of CNPq fellowships. This work also was supported by grants (M.Sc. thesis of Lucas A.D. Nicolau) from $<$ gs2 $>$ Federal University of Piauí, Brazil $<$ | gs>.

\section{References}

[1] I. Villegas, C. La Casa, C.A. de la Lastra, V. Motilva, J.M. Herrerías, M.J. Martín, Mucosal damage induced by preferential COX-1 and COX-2 inhibitors: role of prostaglandins and inflammatory response, Life Sci. 74 (7) (2004) 873-884. 
[2] W.S. Beck, H.T. Schneider, K. Dietzel, B. Nuernberg, K. Brune, Gastrointestinal ulcerations induced by anti-inflammatory drugs in rats, Arch. Toxicol. 64 (3) (1990) 210-217.

[3] J.H. Kim, Y.S. Kim, G.G. Song, J.J. Park, H.I. Chang, Protective effect of astaxanthin on naproxen-induced gastric antral ulceration in rats, Eur. J. Pharmacol. 514 (1) (2005) 53-59.

[4] T. Yoshikawa, Y. Naito, S. Ueda, H. Oyamada, T. Takemura, N. Yoshida, et al., Role of oxygen-derived free radicals in the pathogenesis of gastric mucosal lesions in rats, J. Clin. Gastroenterol. 12 (1990) 65-71.

[5] J.L. Wallace, C.M. Keenan, D.N. Granger, Gastric ulceration induced by nonsteroidal anti-inflammatory drugs is a neutrophil-dependent process, Am. J. Physiol. 259 (3) (1990) 462-467.

[6] N.S. Carvalho, M.M. Silva, R.O. Silva, L.A. Nicolau, F.B. Sousa, S.R. Damasceno Gastroprotective properties of cashew gum, a complex heteropolysaccharide of Anacardium occidentale, in naproxen-induced gastrointestinal damage in rats Drug Develop, Drug Develop. Res. 76 (3) (2015) 143-151.

[7] A.P. Santos, P.R.H. Moreno, Pilocarpus spp.: a survey of its chemical constituents and biological activities, Braz. J. Pharm. Sci. 40 (2) (2004) 115-137.

[8] C.U. Pinheiro, Jaborandi (Pilocarpus sp., Rutaceae): a wild species and its rapid transformation into a crop, Econ. Bot. 51 (1) (1997) 49-58.

[9] M. Andrade-Neto, P.H. Mendes, E.R. Silveira, An imidazole alkaloid and other constituents from Pilocarpus trachyllophus, Phytochemistry 42 (3) (1996) $885-887$.

[10] L.M. Veras, M.A. Guimaraes, Y.D. Campelo, M.M. Vieira, C. Nascimento, D.F. Lima, et al., Activity of epiisopiloturine agaist Schistosoma mansoni, Curr. Med. Chem. 19 (13) (2012) 2051-2058.

[11] V.G. Silva, R.O. Silva, S.R.B. Damasceno, N.S. Carvalho, R.S. Prudêncio, K.S Aragão, et al., Anti-inflammatory and antinociceptive activity of epiisopiloturine, an imidazole alkaloid isolated from Pilocarpus microphyllus, J. Nat. Prod. 76 (6) (2013) 1071-1077.

[12] D.J. Newman, G.M. Cragg, Natural products as sources of new drugs over the 30 years from 1981 to 2010, J. Nat. Prod. 75 (3) (2012) 311-335.

[13] A. Bhatnagar, P.K. Sharma, N. Kumar, A review on imidazoles: their chemistry and pharmacological potentials, Int. J. Pharm. Technol. Res. 3 (2011) 268-282.

[14] R.F. Nascimento, I.R.P. Sales, R.O. Formiga, J.M. Barbosa-Filho, M.V. Sobral, J.F. Tavares, et al., Activity of alkaloids on peptic ulcer: what's new? Molecules 20 (1) (2015) 929-950.

[15] H.W. Voigtländer, G. Balsam, M. Engelhardt, L. Pohl, Epiisopiloturin, ein neues pilocarpus-alkaloid, Arch. Pharm. 311 (1978) 927-935.

[16] G.R. Martin, J.L. Wallace, Gastrointestinal inflammation: a central component of mucosal defense and repair, Exp. Biol. Med. 23 (2006) 130-137.

[17] J. Sedlak, R.H. Lindsay, Estimation of total protein-bound, and nonprotein sulfhydryl groups in tissue with Ellman's reagent, Anal. Biochem. 24 (1968) 1992-2005

[18] M. Mihara, M. Uchiyama, Determination of malonaldehyde precursor in tissues by thiobarbituric acid test, Anal. Biochem. 86 (1978) 271-278.

[19] P.P. Bradley, D.A. Priebat, R.D. Christensen, G. Rothstein, Measurement of cutaneous inflammation: estimation of neutrophil content with an enzyme marker, J. Invest. Dermatol. 78 (3) (1982) 206-209.

[20] L. Laine, W.M. Weinstein, Histology of alcoholic hemorrhagic-gastritis: a prospective evaluation, Gastroenterology 94 (6) (1988) 1254-1262.

[21] M. Shay, S.A. Komarov, S.E. Fels, D. Meranze, M. Gruenstein, H. Siplet, et al., A simple method for the uniform production of gastric ulceration in the rats, Gastroenterology 5 (1945) 43-61.

[22] H. Ancha, H. Ojeas, D. Tedesco, A. Ward, R.F. Harty, Somatostatin-induced gastric protection against ethanol: involviment of nitric oxide and effects on gastric mucosal blood flow, Regul. Peptides 110 (2) (2003) 107-113.
[23] E. Cadar, A. Tomescu, C.L. Erimia, A. Mustafa, R. Sîrbu, The impact of alkaloids structures from natural compounds on public health, Eur. Soc. Sci. Res. 5 (2015) 34-39.

[24] R.E. Pemberton, LJ Strand, A review of upper-gastrointestinal effects of the newer nonsteroidal antinflammatory agents, Dig. Dis. Sci. 24 (1) (1979) 53-64.

[25] R.O. Silva, A.P.M. Santana, N.S. Carvalho, T.S. Bezerra, C.B. Oliveira, S.R. Damasceno, et al., A sulfated polysaccharide fraction from seaweed Gracilaria birdiae prevents naproxen-induced gastrointestinal damage in rats, Mar. Drugs 10 (12) (2012) 2618-2633.

[26] K. Higuchi, E. Umegaki, T. Watanabe, Y. Yoda, E. Morita, M. Murano, et al., Present status and strategy of NSAIDs-induced small bowel injury, J. Gastroenterol. 44 (2009) 879-888.

[27] K. Takeuchi, T. Miyazawa, A. Tanaka, S. Kato, T. Kunikata, Pathogenic importance of intestinal hypermotility in NSAID-induced small intestinal damage in rats, Digestion 66 (2002) 30-41.

[28] B.K. Reuter, N.M. Davies, J.L. Wallace, Nonsteroidal anti-inflammatory drug enteropathy in rats: role of permeability, bacteria and enterohepatic circulation, Gastroenterology 112 (1997) 109-117.

[29] M.H.L.P. Souza, H.P. Lemos, R.B. Oliveira, F.Q. Cunha, Gastric damage and granulocyte infiltration induced by indomethacin in tumour necrosis factor receptor 1 (TNF-R1) or inducible nitric oxide synthase (iNOS) deficient mice, Gut 53 (2004) 791-796.

[30] J.M. Hallett, A.E. Leitch, N.A. Riley, R. Duffin, C. Haslett, A.G. Rossi, Novel pharmacological strategies for driving inflammatory cell apoptosis and enhancing the resolution of inflammation, Trends Pharmacol. Sci. 29 (2008) 250-257.

[31] D. Figarella-Branger, M. Civatte, C. Bartoli, J.F. Pellissier, Cytokines, chemokines and cell adhesion molecules in inflammatory myopathies, Muscle Nerve 28 (2003) 659-682.

[32] I. Brzozowska, A. Targosz, Z. Sliwowski, S. Kwiecien, D. Drozdowicz, R. Pajdo, et al., Healing of chronic gastric ulcers in diabetic rats treated with native aspirin, nitric oxide (NO)-derivative of aspirin and cyclooxygenase (COX)-2 inhibitor, J. Physiol. Pharmacol. 55 (2004) 773-790.

[33] P. Dharmani, C. De Simone, K. Chadee, The probiotic mixture VSL\#3 accelerates gastric ulcer healing by stimulating vascular endothelial growth factor, PLoS One 8 (2013) 58671-58680.

[34] D.A. Parks, G.B. Bulkley, D.N. Granger, S.R. Hamilton, J.M. McCord, Ischemic injury in the cat small intestine: role of superoxide radicals, Gastroenterology 82 (1982) 9-15.

[35] K.A.S. Mahmood, J.H. Ahmed, A. Jawad, Non-steroidal anti-inflammatory drugs (NSAIDs), free radicals and reactive oxygen species (ROS): a review of literature, Med. J. Basrah. Univ. 27 (2009) 46-53.

[36] B. Cryer, Mucosal defense and repair: role of prostaglandins in the stomach and duodenum, Gastroenterol. Clin. North. Am. 30 (2001) 877-894.

[37] L. Laine, S. Harper, T. Simon, R. Bath, J. Johanson, H. Schwartz, et al., A randomized trial comparing the effect of rofecoxib a COX-2 specific inhibitor, to ibuprofen on the gastroduodenal mucosa of osteoarthritis patients, Gastroenterol 17 (1999) 776-783.

[38] J.L. Wallace, NSAID gastroenterophaty: past, present and future, Can. J. Gastroenterol. 10 (1996) 451-459.

[39] J.L. Wallace, G. Caliendo, V. Santagada, G. Cirino, Markedly reduced toxicity of a hydrogen sulphide-releasing derivative of naproxen (ATB-346), Br. J. Pharmacol. 159 (6) (2010) 1236-1246.

[40] K.L. Chaudhary, S. Haddadin, R. Nistala, C. Papageorgio, Intraperitoneal drug therapy: an advantage, Curr. Clin. Pharmacol. 5 (2010) 82-88. 